\title{
Development and application of an innovative expert decision support system to manage sediments and to assess environmental risk in freshwater ecosystems
}

\author{
Alessandro Dagnino ${ }^{\mathrm{a}, *}$, Tiziano Bo ${ }^{\mathrm{a}}$, Andrea Copetta ${ }^{\mathrm{a}}$, Stefano Fenoglio ${ }^{\mathrm{a}}$, Caterina Oliveri ${ }^{\mathrm{a}}$, \\ Mauro Bencivenga ${ }^{\mathrm{b}}$, Angelo Felli ${ }^{\mathrm{b}}$, Aldo Viarengo ${ }^{\mathrm{a}}$ \\ a DiSIT, Università del Piemonte Orientale “Amedeo Avogadro”, Viale Teresa Michel 11, 15121 Alessandria, Italy \\ b ISPRA, Istituto Superiore per la Protezione e la Ricerca Ambientale, Via Vitaliano Brancati 48, 00144 Rome, Italy
}

\section{A R T I C L E I N F O}

\section{Article history:}

Received 26 October 2012

Accepted 18 August 2013

Available online $\mathrm{xxxx}$

\section{Keywords:}

Environmental risk assessment

Freshwater ecosystem management

Decision support system

Triad approach

Genotoxicity biomarker

\begin{abstract}
A B S T R A C T
With the aim of supporting decision makers to manage contamination in freshwater environments, an innovative expert decision support system (EDSS) was developed. The EDSS was applied in a sediment quality assessment along the Bormida river (NW, Italy) which has been heavily contaminated by an upstream industrial site for more than a century. Sampling sites were classified by means of comparing chemical concentrations with effect-based target values (threshold and probable effect concentrations). The level of each contaminant and the combined toxic pressure were used to rank sites into three categories: (i) uncontaminated ( 8 sites), (ii) mildly contaminated (4) and (iii) heavily contaminated (19). In heavily contaminated sediments, an environmental risk index (EnvRI) was determined by means of integrating chemical data with ecotoxicological and ecological parameters (triad approach). In addition a sediment risk index (SedRI) was computed from combining chemical and ecotoxicological data. Eight sites exhibited EnvRI values $\geq 0.25$, the safety threshold level (range of EnvRI values: 0.140.31 ) whereas SedRI exceeded the safety threshold level at 6 sites (range of SedRI values: 0.16-0.36). At sites classified as mildly contaminated, sublethal biomarkers were integrated with chemical data into a biological vulnerability index (BVI), which exceeded the safety threshold level at one site (BVI value: 0.28 ). Finally, potential human risk was assessed in selected stations (11 sites) by integrating genotoxicity biomarkers (GTI index falling in the range 0.00-0.53). General conclusions drawn from the EDSS data include: (i) in sites classified as heavily contaminated, only a few exhibited some significant, yet limited, effects on biodiversity; (ii) restrictions in reusing sediments from heavily contaminated sites found little support in ecotoxicological data; (iii) in the majority of the sites classified as mildly contaminated, tested organisms exhibited low response levels; (iv) preliminary results on genotoxicity biomarkers indicate possible negative consequences for humans if exposed to river sediments from target areas.
\end{abstract}

(c) 2013 Elsevier Ltd. All rights reserved.

\section{Introduction}

Over the last decade the political awareness of river quality has grown in many countries (European Commission, 2000; Horn et al., 2004; US EPA, 2008). As a consequence, multidisciplinary approaches combining chemical, ecotoxicological and ecological data in accordance with the Triad approach have been developed around the world (Alvarez-Guerra et al., 2009; Bay and Weisberg, 2012; Benedetti et al., 2012; de Deckere et al., 2011; McDonald et al., 2007). The rationale for using a more integrated approach is that adverse biological effects induced by exposure to complex pollutant mixtures are not easily interpreted from a set of chemical analyses (de Zwart and Posthuma, 2005). Rather, the toxic effect of different interacting pollutants can be either additive, synergistic or antagonistic (Jonker et al., 2005).

\footnotetext{
* Corresponding author. Tel.: + 390131 360384; fax: + 390131360390.

E-mail addresses: dagnino@unipmn.it, aledagnino@virgilio.it (A. Dagnino).
}

As of August 2013, more than 297,000 hazardous, chemical substances are regulated for different aspects by governmental bodies around the world (CAS, 2013). However, the number of potentially hazardous chemicals is ever growing, rendering a complete chemical characterization of contaminants almost impossible (Vink et al., 1999). This is particularly true for freshwater systems often characterized by diffuse pollution sources (van Straalen and van Gestel, 2008) and complex contamination mixtures (Holt, 2000). Individual pollutants are compartmentalized in different matrices, i.e. water, suspended solids, sediment and pore-water. Sediments are often pollution sinks that may reduce water quality and cause environmental deterioration although water column concentrations comply with established environmental quality standards (EQSs) (Larsson, 1985; Salomons et al., 1987; US EPA, 2003, 2005).

Sediment evaluation strategies can be divided into two main categories depending on the specific management goal: (i) addressing environmental risks associated with dredging activities; (ii) assessing 
the ecological quality status of the river basin (den Besten et al., 2003; Heise et al., 2004). In the former case, a chemical and ecotoxicological characterization of dredged sediments assists in predicting risks related to sediment resuspension (Apitz and Power, 2002). In the latter case, a Triad-based ecological risk assessment is usually applied, i.e. an assessment that integrates chemical, ecotoxicological and ecological data (Chapman, 2007).

However, the selection of ecologically relevant model organisms in ecotoxicological tests represents a critical point to obtain realistic results. In this regard, test organisms should represent different trophic levels in the assessed lotic or lentic environments, i.e. detritus-feeders and grazing organisms (Fenoglio and Bo, 2009; Hynes, 1970).

The aim of this study has been to develop an Expert Decision Support System (EDSS) with two main characteristics: (i) the possibility to objectively integrate chemical and ecotoxicological data to assess environmental impact of polluted sediments by applying a tiered integration framework; (ii) the possibility to assess the environmental risk related to contamination of freshwater ecosystems by applying a weightof-evidence Triad approach. Main features in establishing the EDSS integration framework have been (i) to calculate the toxic pressure of chemicals present in a sample (Jensen and Mesman, 2006), and (ii) to analyze biomarkers, i.e. early warning sublethal parameters and higher level effects (mortality and reproduction) separately (Dagnino et al., 2008).

The EDSS was used to assess sediment samples from 31 different stations along the Bormida river (NW, Italy), up- and down-stream a site of national interest (ACNA), which was heavily contaminated from 1882 to 1999 e.g. from the production of explosives, dyes and their intermediates (D'Annibale et al., 2006; Marengo et al., 2006; Massa et al., 2010). Several pollutants, most notably heavy metals, PAHs, chlorinated benzenes, anilines and thiophenes were released into the Bormida river leading to a severe environmental impact.

\section{Materials and methods}

\subsection{Framework for environmental risk and sediment quality assessment}

A tiered framework is proposed to integrate Triad data into an environmental risk index and to combine chemical and ecotoxicological results in the evaluation of sediment-associated risk (Fig. 1). With the aim to assess the degree of sediment contamination, chemical concentrations, both as single compounds and the overall toxic pressure TPC $_{\mathrm{TEC}}$ and

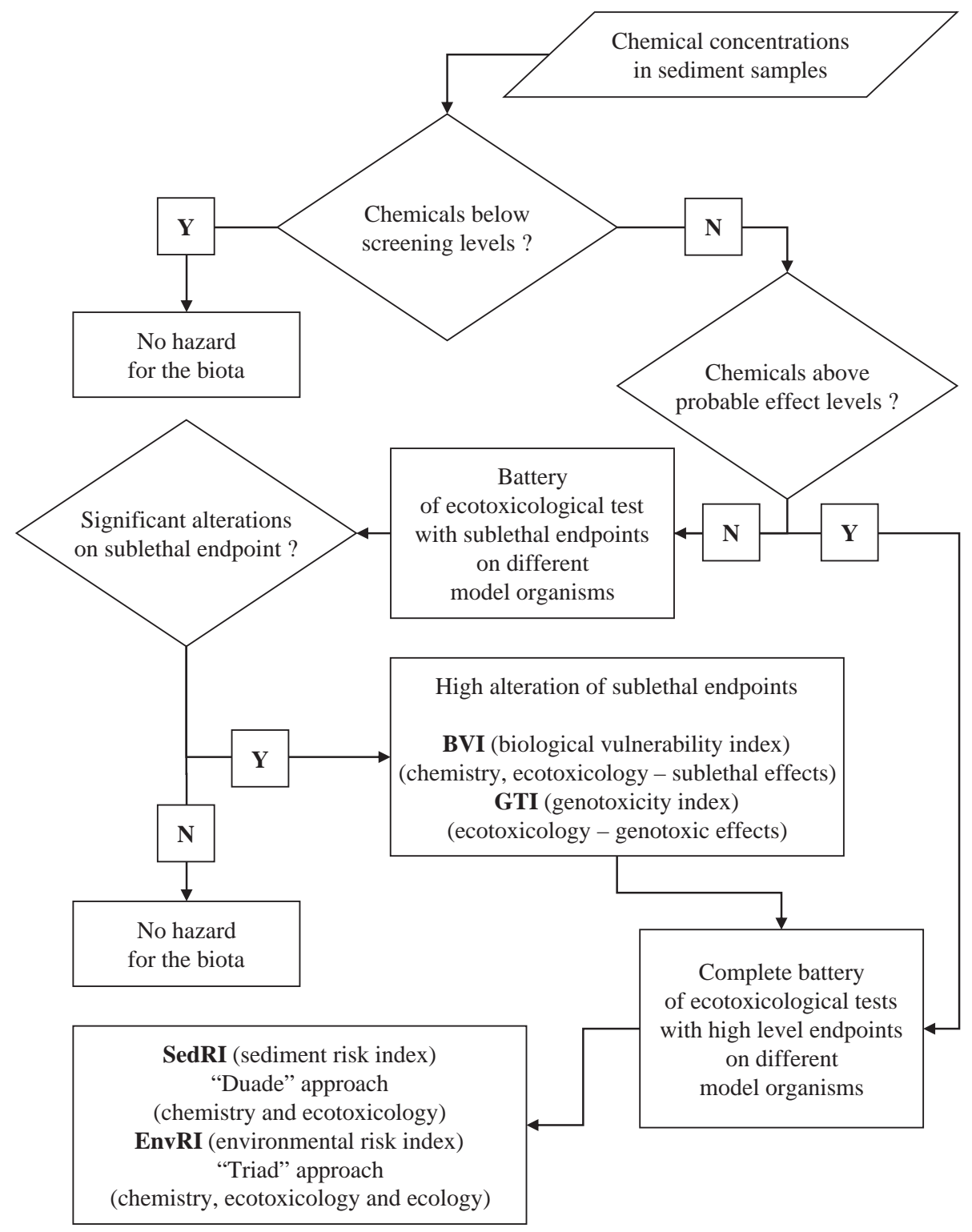

Fig. 1. Integration of triad data. Framework for the integration of chemical and ecotoxicological data developed for freshwater sediment assessment. 
$\mathrm{TPC}_{\mathrm{PEC}}$ indices), are compared to EQSs (i.e. TEC, threshold effect concentrations, and PEC, probable effect concentration) proposed by MacDonald et al. (2000) and recently updated for application in Italian freshwater sediments (ISPRA, 2011). If an EQS is not available for a particular contaminant, it should be derived by either of the following methods: (i) applying Quantitative Structure-Activity Relationship models (Papa et al., 2005); (ii) analyzing the scientific bibliography and extrapolating TEC and PEC from species sensitivity distribution curves (Newman et al., 2000); (iii) analyzing directly in the laboratory the toxicological effects in different model organisms (van der Hoeven, 2004).

Sediments with concentrations of each contaminant below its TEC and with overall toxic pressure $\left(\mathrm{TPC}_{\mathrm{TEC}}\right.$ ) below a critical threshold are considered "uncontaminated". Sediments containing concentrations above relevant PECs, either as single contaminants or as an overall toxic pressure $\left(\mathrm{TPC}_{\mathrm{PEC}}\right)$, are classified as "heavily contaminated". In this case high level endpoints (i.e. survival and reproduction rate) are tested on model organisms to assess possible effects at the organism and population levels. Finally, sediments with concentrations falling in the range between TEC and PEC, and with the overall toxic pressure $\left(\mathrm{TPC}_{\mathrm{TEC}}\right)$ above a critical threshold level are classified as "mildly contaminated", rendering necessary a battery of sublethal biomarkers to define the potential effects induced on biota (Burton et al., 2000; Keddy et al., 1995; Norberg-King et al., 2006; Sforzini et al., 2008; Smutna et al., 2008).

For sediments classified as "heavily contaminated", an environmental risk index (EnvRI) and a sediment risk index (SedRI) are calculated. For sediment samples classified as "mildly contaminated", a biological vulnerability index (BVI) is determined. Finally, where possible, genotoxic data are used to compute a Genotoxicity Index (GTI).

\subsubsection{Analysis of chemical data}

2.1.1.1. Selection of the environmental quality standards. With the aim of quantifying the potential hazards related to chemical contamination in sediment samples, two EQSs (TEC and PEC) were defined for each pollutant, on the basis of the available scientific bibliography and on European and national legislation (Table 1).

2.1.1.2. Calculation of the toxic pressure coefficients. For each sediment sample, two toxic pressure coefficients are computed. Background levels of naturally occurring elements are subtracted from analyzed chemical concentrations in the sample following the added risk approach (Struijs et al., 1997). For each contaminant, chemical added concentrations are divided by their respective TECs and the ratios are summed to calculate a total toxic pressure coefficient (TPC $\mathrm{TEC}_{\mathrm{TEC}}$ ) (Eq. (1)). Similarly, a second toxic pressure coefficient $\left(\mathrm{TPC}_{\mathrm{PEC}}\right.$ ) is computed by dividing added concentrations in sediments by relevant PECs and summing the ratios for each pollutant (Eq. (2)).

$\mathrm{TPC}_{\mathrm{TEC}}=\sum \frac{\left(\mathrm{C}_{\mathrm{i}}-\mathrm{C}_{\mathrm{i}}^{\mathrm{b}}\right)}{\mathrm{TEC}_{\mathrm{i}}}$

$\mathrm{TPC}_{\mathrm{PEC}}=\sum \frac{\left(\mathrm{C}_{\mathrm{i}}-\mathrm{C}_{\mathrm{i}}^{\mathrm{b}}\right)}{\mathrm{PEC}_{\mathrm{i}}}$

where

$\mathrm{C}_{\mathrm{i}} \quad$ concentration of $\mathrm{i}$-th contaminant in the sediment sample;

$\mathrm{C}_{\mathrm{i}}^{\mathrm{b}} \quad$ background concentration of the $\mathrm{i}$-th contaminant (for natural occurring elements);

$\mathrm{TEC}_{\mathrm{i}}$ threshold effect concentration for the i-th contaminant (Table 1);

$\mathrm{PEC}_{\mathrm{i}} \quad$ probable effect concentration for the i-th contaminant (Table 1).
2.1.1.3. Classification of sediment samples. Chemical concentrations are compared to EQSs (i.e. TEC and PEC) and the corresponding TPC values with chosen critical levels. Sediment samples are then classified as being either "uncontaminated", "mildly contaminated" or "heavily contaminated" (Fig. 2). Critical levels of $\mathrm{TPC}_{\mathrm{TEC}}$ and $\mathrm{TPC}_{\mathrm{PEC}}$ are conservatively set equal to 1 .

2.1.1.4. Derivation of the chemical risk index. A chemical risk index (ChemRI) in the range $0-1$, is derived by comparing $\mathrm{TPC}_{\mathrm{TEC}}$ with threshold values (Eq. (3)).

$\begin{array}{lll}\text { Case 1 : } & \mathrm{TPC}_{\mathrm{TEC}}<\mathrm{Th}_{1} & \text { ChemRI }=\alpha_{1} \cdot \frac{\mathrm{TPC}_{\mathrm{TEC}}}{\mathrm{Th}_{1}} \\ \text { Case 2 : } & \mathrm{Th}_{1} \leq \mathrm{TPC}_{\mathrm{TEC}}<\mathrm{Th}_{2} & \text { ChemRI }=\alpha_{1}+\left(\alpha_{2}-\alpha_{1}\right) \cdot \frac{\left(\mathrm{TPC}_{\mathrm{TEC}}-\mathrm{Th}_{1}\right)}{\left(\mathrm{Th}_{2}-\mathrm{Th}_{1}\right)} \\ \text { Case 3: } & \mathrm{Th}_{2} \leq \mathrm{TPC}_{\mathrm{TEC}}<\mathrm{Th}_{3} & \text { ChemRI }=\alpha_{2}+\left(1-\alpha_{2}\right) \cdot \frac{\left(\mathrm{TPC}_{\mathrm{TEC}}-\mathrm{Th}_{2}\right)}{\left(\mathrm{Th}_{3}-\mathrm{Th}_{2}\right)} \\ \text { Case 4: } & \mathrm{TPC}_{\mathrm{TEC}} \geq \mathrm{Th}_{3} & \text { ChemRI }=1\end{array}$

where

$\mathrm{TPC}_{\mathrm{TEC}} \quad$ toxic pressure coefficient computed using TECs;

$\mathrm{Th}_{1}, \mathrm{Th}_{2}, \mathrm{Th}_{3}$ thresholds for $\mathrm{TPC}_{\mathrm{TEC}}$;

$\alpha_{1}, \alpha_{2} \quad$ ChemRI values correspondent to a TPC values equal to $\mathrm{Th}_{1}$ and $\mathrm{Th}_{2}$.

A graphical representation of Eq. (3) is shown in Fig. 3.

\subsubsection{Analysis of biological data}

Biological data are used to derive three different indices: (i) an ecotoxicological risk index, EtoxRI, integrating high level toxicological responses; (ii) a biological stress index, BSI, integrating the results from sublethal biomarker tests; (iii) an ecological risk index, EcoRI, merging effects on ecosystem structure and functions. EtoxRI and EcoRI are computed for sites classified as "heavily contaminated", while BSI is calculated for sites classified as "mildly contaminated". Both EtoxRI and EcoRI are calculated for the reference site(s).

High level ecotoxicological responses that hence are indicative of potential effects at the population level, such as mortality or reproduction rates, are compared with control samples. Differences (RtR) are then compared using two different thresholds (Semenzin et al., 2008): (i) a first threshold defining a minimal alteration level that can be considered as natural fluctuation $\left(\mathrm{Th}_{1}\right)$; (ii) a second threshold defining a strong alteration level above which the parameter can be considered heavily altered $\left(\mathrm{Th}_{2}\right)$. After comparison with threshold values, RtR is converted to an alteration index (AI) in the range $0-1$ (Eq. (4)).

$$
\begin{array}{lll}
\text { Case 1: } & \mathrm{RtR}_{\mathrm{i}}<\mathrm{Th}_{1, \mathrm{i}} & \mathrm{AI}_{\mathrm{i}}=0 \\
\text { Case 2: } & \mathrm{Th}_{1, \mathrm{i}} \leq \mathrm{RtR}_{\mathrm{i}}<\mathrm{Th}_{2, \mathrm{i}} & \mathrm{AI}_{\mathrm{i}}=\frac{\left(\mathrm{RtR}_{\mathrm{i}}-\mathrm{Th}_{1, \mathrm{i}}\right)}{\left(\mathrm{Th}_{2, \mathrm{i}}-\mathrm{Th}_{1, \mathrm{i}}\right)} \\
\text { Case 3 : } & \mathrm{RtR}_{\mathrm{i}} \geq \mathrm{Th}_{2, \mathrm{i}} & \mathrm{AI}_{\mathrm{i}}=1
\end{array}
$$

where

$\mathrm{RtR}_{\mathrm{i}} \quad$ ratio to reference for the $\mathrm{i}$-th ecotoxicological test;

$\mathrm{Th}_{1, \mathrm{i}}, \mathrm{Th}_{2, \mathrm{i}}$ first and second thresholds for the i-th ecotoxicological test; $\mathrm{AI}_{\mathrm{i}} \quad$ alteration index for the $\mathrm{i}$-th ecotoxicological test.

A graphical representation of Eq. (4) is shown in Fig. 4.

Finally, an ecotoxicological risk index (EtoxRI) is computed as the mean value of AIs for all high level ecotoxicological tests performed on samples from the same station.

Similarly, results from sub-lethal biomarker tests are compared with control samples; the relative alterations are then used to calculate an AI 
Table 1

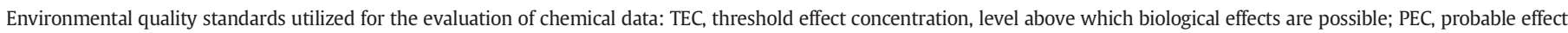

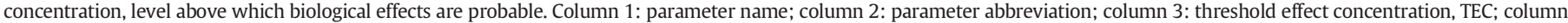
4: probable effect concentration, PEC; column 5: unit of measure; column 6: reference for TEC and PEC.

\begin{tabular}{|c|c|c|c|c|c|}
\hline Parameter & Abbr. & TEC & PEC & Unit of measure & Reference \\
\hline Antimony & $\mathrm{Sb}$ & 11.20 & 25 & $\mathrm{mg} \mathrm{kg}^{-1}$ & European Union (2008), Italian Government (2006) \\
\hline Arsenic & As & 9.79 & 33 & $\mathrm{mg} \mathrm{kg}^{-1}$ & MacDonald et al. (2000) \\
\hline Cadmium & $\mathrm{Cd}$ & 0.99 & 4.98 & $\mathrm{mg} \mathrm{kg}^{-1}$ & MacDonald et al. (2000) \\
\hline Chromium & $\mathrm{Cr}$ & 43.40 & 111 & $\mathrm{mg} \mathrm{kg}^{-1}$ & MacDonald et al. (2000) \\
\hline Iron & $\mathrm{Fe}$ & 20,000 & 40,000 & $\mathrm{mg} \mathrm{kg}^{-1}$ & Persaud et al. (1993) \\
\hline Manganese & Mn & 460 & 1100 & $\mathrm{mg} \mathrm{kg}^{-1}$ & Persaud et al. (1993) \\
\hline Mercury & $\mathrm{Hg}$ & 0.18 & 1.06 & $\mathrm{mg} \mathrm{kg}^{-1}$ & MacDonald et al. (2000) \\
\hline Nickel & $\mathrm{Ni}$ & 22.70 & 48.60 & $\mathrm{mg} \mathrm{kg}^{-1}$ & MacDonald et al. (2000) \\
\hline Lead & $\mathrm{Pb}$ & 35.80 & 128 & $\mathrm{mg} \mathrm{kg}^{-1}$ & MacDonald et al. (2000) \\
\hline Copper & $\mathrm{Cu}$ & 31.60 & 149 & $\mathrm{mg} \mathrm{kg}^{-1}$ & MacDonald et al. (2000) \\
\hline Selenium & $\mathrm{Se}$ & 1.30 & 140 & $\mathrm{mg} \mathrm{kg}^{-1}$ & van Vlaardingen et al. (2005) \\
\hline Tin & Sn & 75 & 5600 & $\mathrm{mg} \mathrm{kg}^{-1}$ & van Vlaardingen et al. (2005) \\
\hline Vanadium & $\mathrm{V}$ & 42 & 66 & $\mathrm{mg} \mathrm{kg}^{-1}$ & van Vlaardingen et al. (2005) \\
\hline Zinc & $\mathrm{Zn}$ & 121 & 459 & $\mathrm{mg} \mathrm{kg}^{-1}$ & MacDonald et al. (2000) \\
\hline 2,4,6-tricholoraniline & TCA & 0.05 & 5 & $\mu g \mathrm{~kg}^{-1}$ & Italian Government (2006) \\
\hline 1,2,4-Trichlorbenzene & TCB & 1 & 50 & $\mu \mathrm{g} \mathrm{kg}-1$ & Italian Government (2006) \\
\hline 4-Methylphenol & $\mathrm{MPh}$ & 0.10 & 25 & $\mu \mathrm{g} \mathrm{kg}^{-1}$ & Italian Government (2006) \\
\hline Phenol & $\mathrm{Ph}$ & 1 & 60 & $\mu \mathrm{g} \mathrm{kg}^{-1}$ & Italian Government (2006) \\
\hline Acenaphthylene & ANPh & 5 & 50 & $\mu \mathrm{gg}^{-1}$ & Italian Government (2006) \\
\hline Anthracene & ANT & 5 & 50 & $\mu \mathrm{g} \mathrm{kg}^{-1}$ & Italian Government (2006) \\
\hline Benzo(a)anthracene & $\mathrm{BaA}$ & 0.50 & 10 & $\mu \mathrm{g} \mathrm{kg}^{-1}$ & Italian Government (2006) \\
\hline Benzo(a)pyrene & $\mathrm{BaP}$ & 0.10 & 10 & $\mu \mathrm{g} \mathrm{kg}^{-1}$ & Italian Government (2006) \\
\hline Benzo(b)fluoranthene & $\mathrm{BbF}$ & 0.50 & 10 & $\mu \mathrm{g} \mathrm{kg}^{-1}$ & Italian Government (2006) \\
\hline Benzo(g,h,i)perylene & BghiP & 0.10 & 10 & $\mu \mathrm{g} \mathrm{kg}^{-1}$ & Italian Government (2006) \\
\hline Benzo(k)fluoranthene & $\mathrm{BkF}$ & 0.50 & 10 & $\mu \mathrm{g} \mathrm{kg}^{-1}$ & Italian Government (2006) \\
\hline Chrysene & $\mathrm{Chr}$ & 5 & 50 & $\mu \mathrm{g} \mathrm{kg}^{-1}$ & Italian Government (2006) \\
\hline Phenanthrene & $\mathrm{PhA}$ & 5 & 50 & $\mu \mathrm{g} \mathrm{kg}^{-1}$ & Italian Government (2006) \\
\hline Fluoranthene & FlA & 5 & 50 & $\mu \mathrm{g} \mathrm{kg}^{-1}$ & Italian Government (2006) \\
\hline Indeno( $1,2,3, \mathrm{~cd})$ pyrene & IndPyr & 0.10 & 5 & $\mu \mathrm{gg}^{-1}$ & Italian Government (2006) \\
\hline Naphthalene & Nap & 5 & 50 & $\mu \mathrm{g} \mathrm{kg}^{-1}$ & Italian Government (2006) \\
\hline Pyrene & Pyr & 5 & 50 & $\mu \mathrm{g} \mathrm{kg}^{-1}$ & Italian Government (2006) \\
\hline
\end{tabular}

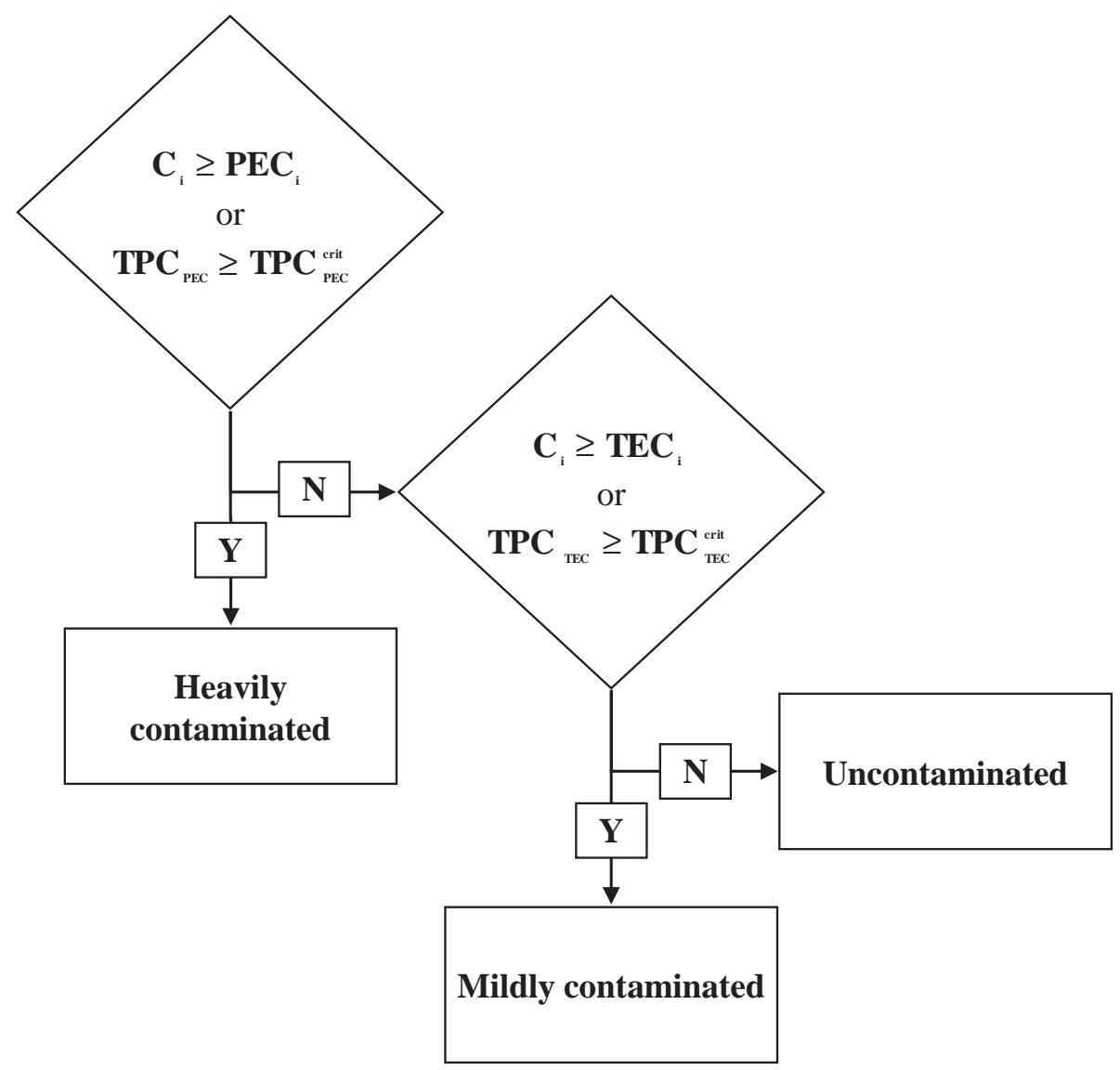

Fig. 2. Sediment classification. Flow diagram showing the classification rules for sediments on the basis of the concentration of chemicals. 


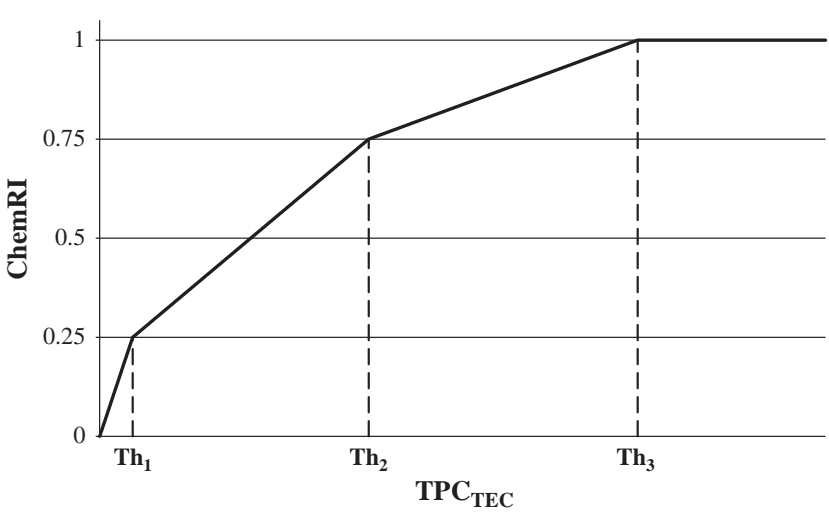

Fig. 3. Curve for ChemRI calculation. Graphical representation of the relationship between ChemRI and $\mathrm{TPC}_{\mathrm{TEC}}$. TPC $\mathrm{CEC}_{\mathrm{TEC}}$ values below $\mathrm{Th}_{1}$ corresponded to ChemRI values lower than 0.25 ; $\mathrm{TPC}_{\mathrm{TEC}}$ values between $\mathrm{Th}_{1}$ and $\mathrm{Th}_{2}$ corresponded to ChemRI values between 0.25 and 0.75 ; values of ChemRI in the range $0.75-1.00$ were attributed to samples showing $\mathrm{TPC}_{\mathrm{TEC}}$ values between $\mathrm{Th}_{2}$ and $\mathrm{Th}_{3}$; the highest ChemRI value (i.e. 1.00) was attributed to samples showing $\mathrm{TPC}_{\mathrm{TEC}}$ values higher than $\mathrm{Th}_{3}$.

in the range $0-1$ for each analyzed endpoint (Eq. (4)); a biological stress index (BSI) is then computed as the mean value of AIs for sublethal biomarkers.

Alterations in ecological data are analyzed by comparing the results from all investigated sites with those from the reference site(s), and by computing the AI for each parameter (Eq. (4)). However, the calculation of the AIs for some ecological data (e.g. for the index describing alterations of community structures) is made directly by comparing the indexed value with the threshold specific for that index (Eq. (4)). Ecological AIs are then used to calculate an ecological risk index (EcoRI) in the range $0-1$ as the mean value of Als derived from ecological parameters.

\subsubsection{Assessment of the risk indexes}

2.1.3.1. Calculation of the environmental risk index. Sites where sediments have been classified as "heavily contaminated" are further characterized by the calculation of an environmental risk index, EnvRI (in the range 0-1), combining ChemRI, EtoxRI and EcoRI, following a triad-based framework. EnvRI is calculated applying weighting factors based on the ecological relevance of the different disciplines (Eq. (5)), 1, 1.5 and 2, respectively, for ChemRI, EtoxRi and EcoRI.

The EnvRI is used to define significant effects on biodiversity, and to identify sites where remediation actions are recommended.

EnvRI $=\frac{\text { wf }_{\text {ChemRI }} \cdot \text { ChemRI }+w_{\text {EtoxRI }} \cdot \text { EtoxRI }+w_{\text {EcoRI }} \cdot \text { EcoRI }}{w_{\text {ChemRI }}+\mathrm{wf}_{\text {EtoxRI }}+\mathrm{wf}_{\text {EcoRI }}}$

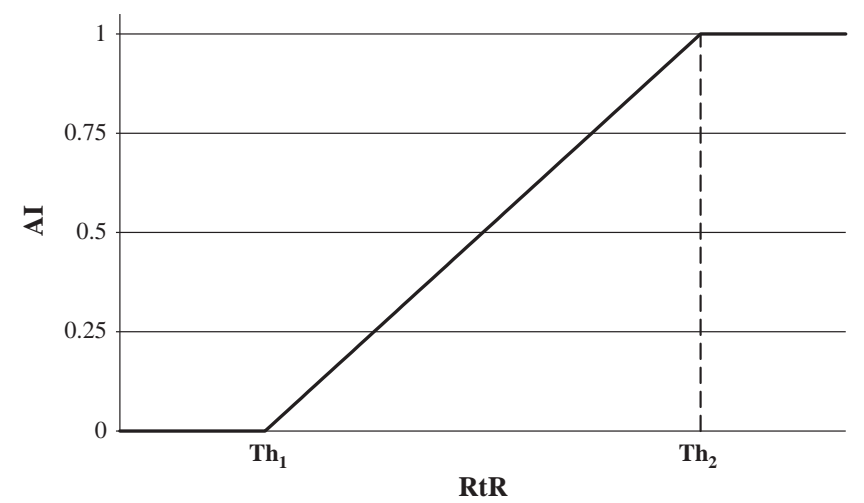

Fig. 4. Curve for the calculation of the Alteration Index. Graphical representation of the relationship between the alteration index $(\mathrm{AI})$ and the percent of variation versus the control for each ecotoxicological test. where

$\mathrm{wf}_{\text {ChemRI}}, \mathrm{wf}_{\text {EtoxRI }}, \mathrm{wf}_{\text {EcoRI }}$ weighting factors applied to each risk index.

2.1.3.2. Calculation of the sediment risk index. At sites where sediments have been classified as "heavily contaminated", a sediment risk index (SedRI) in the range $0-1$ is calculated as the mean of calculated ChemRI and EtoxRI.

SedRI represents a valuable support for decision-making related to dredging activities in defining the hazard related to remobilization of contaminated materials from the riverbed.

2.1.3.3. Calculation of the biological vulnerability index. In sites where sediments have been classified as "mildly contaminated", a biological vulnerability index (BVI) in the range $0-1$ is calculated as the mean value of ChemRI and BSI.

BVI is used to identify sites where, although chemical concentrations are found to be below effect levels, organisms suffer from sublethal stress as evidenced in biomarker tests.

2.1.3.4. Calculation of the genotoxicity index. Some biomarkers can be used to assess genotoxic effects, e.g. DNA damage with the comet assay, micronuclei frequency and mitotic anomalies. The use of such biomarkers allows computing a particular index, called the genotoxicity index (GTI), and addressing general genotoxic risk including human health risks. AIs for each genotoxicity biomarker in the test battery are computed (Eq. (4)); GTI is the mean value of the AIs obtained biomarker tests assessing genotoxicity.

\subsection{Case study: the Bormida river}

\subsubsection{Sampling activities}

Superficial sediment samples $(0-20 \mathrm{~cm})$ were collected from 31 different stations along the Bormida river (NW, Italy), up- and downstream a contaminated site of national interest (Fig. 5, Table 2) during April-May 2006 using a hand corer. Samples were stored at $4{ }^{\circ} \mathrm{C}$ and transported to the laboratories for chemical and ecotoxicological analyses. Sediments were also characterized by means of grain size, $\mathrm{pH}$ and organic carbon content. Moreover, a survey of the benthic macroinvertebrate community was performed from the same samples.

\subsubsection{Chemical analysis}

Sediment extracts were previously analyzed for target pollutants in the laboratories of CeSTA (Centro Sviluppo Tecnologie Ambientali, Cengio, Italy). Target chemicals were selected by the Italian Environmental Protection Agency based on the results from previous studies performed in the area and on the previous industrial activities realized at the contaminated site.

The analysis of metals and metalloids was carried out by means of ICP-MS (Inductively Coupled Plasma-Mass Spectrometry): each sediment sample (1.0 g) was mineralized in microwave oven (internal standard: Tb $1000.0 \mathrm{mg} \mathrm{L}^{-1}$ ) using hydrogen peroxide, nitric acid, and hydrochloric acid; inorganic compounds (i.e. As, $\mathrm{Cd}, \mathrm{Cr}, \mathrm{Cu}, \mathrm{Fe}, \mathrm{Hg}$, $\mathrm{Mn}, \mathrm{Ni}, \mathrm{Pb}, \mathrm{Sb}, \mathrm{Se}, \mathrm{Sn}, \mathrm{V}, \mathrm{Zn}$ ) in the solution were then determined by ICS-MS (internal standards: Rh $100.0 \mu \mathrm{g} \mathrm{L}^{-1}$ and Au $200.0 \mu \mathrm{g} \mathrm{L}^{-1}$ ) with a X5 ThermoElemental (Winsford, UK).

Contamination levels of a choice of organic pollutants (i.e. 2,4,6tricholoraniline, 1,2,4-trichlorbenzene, 4-methylphenol, phenol, acenaphthylene, anthracene, benzo(a)anthracene, benzo(a)pyrene, benzo(b)fluoranthene, benzo(g,h,i)perylene, benzo(k)fluoranthene, chrysene, phenanthrene, fluoranthene, indeno(1,2,3-cd)pyrene, naphthalene, pyrene) were determined by means of GC-MS (Gas Chromatography-Mass Spectrometry, Agilent Technologies Inc., model 5973) after accelerated solvent extraction with dichloromethane. 


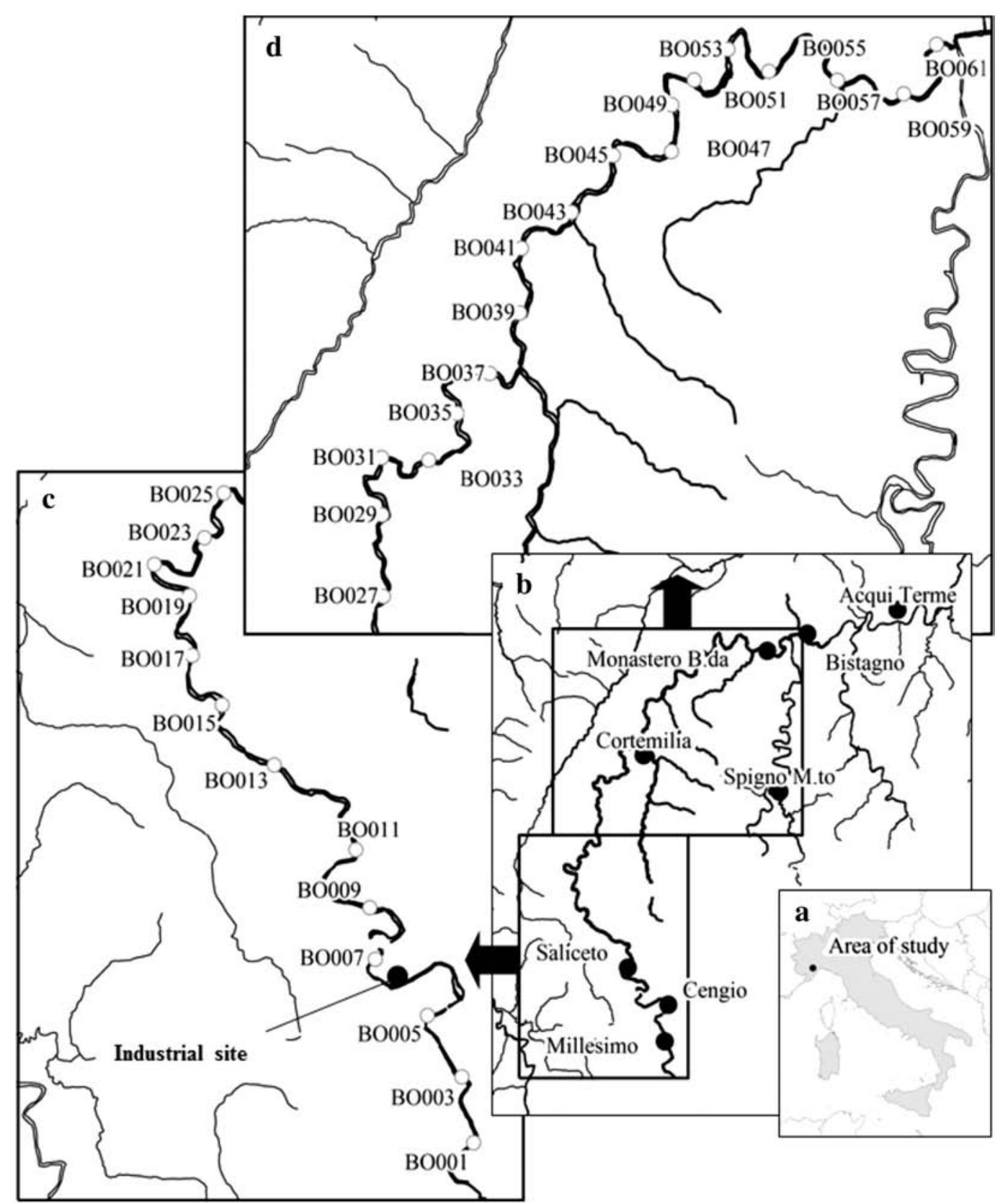

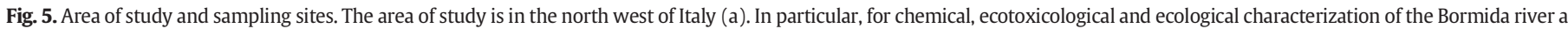
stretch of about $60 \mathrm{~km}$ was investigated (b). Thirty-one sampling stations were placed along the river, up- and down-stream the ACNA industrial site (c and d).

Parameters used for calculating ChemRI values (Eq. (3)) are reported in Table 3. The values of $\mathrm{Th}_{2}$ and $\mathrm{Th}_{3}$ are calculated on the basis of TECs and PECs (Eq. (6)).

$$
\begin{aligned}
\mathrm{Th}_{2} & =\frac{1}{\mathrm{n}} \cdot \sum \frac{\mathrm{PEC}_{\mathrm{i}}}{\mathrm{TEC}_{\mathrm{i}}} \\
\mathrm{Th}_{3} & =2 \cdot \frac{1}{\mathrm{n}} \cdot \sum \frac{\mathrm{PEC}_{\mathrm{i}}}{\mathrm{TEC}_{\mathrm{i}}}
\end{aligned}
$$

where

$\mathrm{Th}_{2}, \mathrm{Th}_{3}$ second and third threshold values to calculate ChemRI (Eq. (3)); $\mathrm{n}$ number of analyzed chemicals;

$\frac{\mathrm{PEC}_{\mathrm{i}}}{\mathrm{TEC}}$ ratio between probable and threshold effect concentrations for the i-th contaminant.

\subsubsection{Ecotoxicological analysis}

Sediments (pore-water and whole-sediment) were analyzed applying a battery of high level and sublethal ecotoxicological tests in bacteria, protozoans, mono- and dicotyledonous plants, nematodes, and crustaceans following site classifications shown in Table 4.

2.2.3.1. Sediment preparation. Sediments were manually homogenized and pore-water samples were obtained by centrifugation $(3000 \mathrm{rpm}$, $30 \mathrm{~min}, 15^{\circ} \mathrm{C}$ ) of wet sediments. Sediments were then dried at room temperature, crushed, and sieved over a $2 \mathrm{~mm}$ mesh sieve (Carr and Chapman, 1995).

To guarantee the reliability of ecotoxicological data, model organisms were also exposed to control media as stated by the standard protocol of each test, and the results were checked with test-specific acceptability parameters. 
Table 2

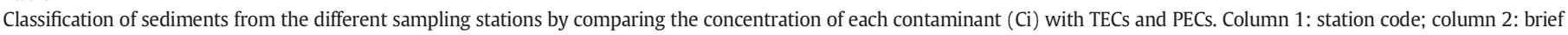

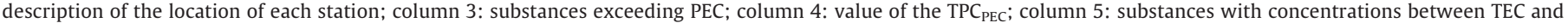

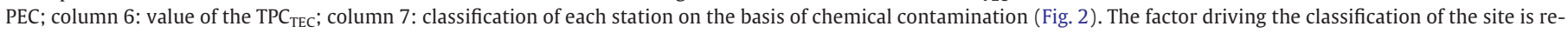
ported in bold (columns 3-6).

\begin{tabular}{|c|c|c|c|c|c|c|}
\hline Station code & Location & $\mathrm{Ci}>\mathrm{PEC}$ & $\mathrm{TPC}_{\mathrm{PEC}}$ & $\mathrm{TEC} \leq \mathrm{Ci} \leq \mathrm{PEC}$ & $\mathrm{TPC}_{\mathrm{TEC}}$ & Classification \\
\hline BO001 & Millesimo, upstream the urban area & & 0.11 & & 0.33 & Uncontam. \\
\hline В0003 & Millesimo, downstream the urban area & & 0.03 & & 0.28 & Uncontam. \\
\hline BO005 & Cengio, upstream the industrial site & & 0.06 & ANT & 1.99 & Mildly contam. \\
\hline BO007 & Cengio, downstream the industrial site & & 1.58 & Mn, TCA, MPh, ANPh, ANT & 14.07 & Heavily contam. \\
\hline BO009 & Saliceto, upstream the urban area & & 0.17 & ANT & 2.91 & Mildly contam. \\
\hline BO011 & Saliceto, downstream the urban area & $\mathrm{Cr}, \mathrm{Ni}$ & 3.96 & & 9.47 & Heavily contam. \\
\hline B0013 & Camerana, upstream the urban area & $\mathrm{Ni}$ & 1.75 & $\mathrm{Cr}$ & 4.29 & Heavily contam. \\
\hline BO015 & Camerana, downstream the urban area & & 0.00 & & 0.14 & Uncontam. \\
\hline BO017 & Monesiglio, upstream the urban area & & 0.51 & & 3.82 & Mildly contam. \\
\hline B0019 & Monesiglio, downstream the urban area & $\mathrm{Cr}, \mathrm{Ni}$ & 4.87 & & 11.44 & Heavily contam. \\
\hline BO021 & Gorzegno, upstream the urban area & & 0.00 & & 0.13 & Uncontaminated \\
\hline BO023 & Gorzegno, upstream the urban area & & 0.00 & & 0.15 & Uncontaminated \\
\hline BO025 & Gorzegno, downstream the urban area & & 0.16 & & 0.57 & Uncontaminated \\
\hline BO027 & Levice & TCB & 6.38 & $\mathrm{Ni}$ & 15.37 & Heavily contam. \\
\hline BO029 & Torre Bormida, upstream the urban area & TCB & 7.06 & $\mathrm{Ni}$ & 16.35 & Heavily contam. \\
\hline B0031 & Torre Bormida, upstream the urban area & $\mathrm{Cr}, \mathrm{Ni}$ & 4.91 & & 11.78 & Heavily contam. \\
\hline B0033 & Torre Bormida, downstream the urban area & & 0.02 & & 0.15 & Uncontam. \\
\hline BO035 & Cortemiglia, upstream the urban area & $\mathbf{N i}$ & 3.03 & $\mathrm{Cr}$ & 7.57 & Heavily contam. \\
\hline BO037 & Cortemiglia & & 1.66 & $\mathrm{Cr}, \mathrm{Ni}$ & 4.11 & Heavily contam. \\
\hline В0039 & Cortemiglia, downstream the urban area & & 0.33 & & 0.95 & Uncontam. \\
\hline B0041 & Cortemiglia, downstream the urban area & & 1.18 & $\mathrm{Cr}, \mathrm{Ni}$ & 2.98 & Heavily contam. \\
\hline BO043 & Vesime, upstream the urban area & $\mathrm{Cr}, \mathrm{Ni}$ & 3.21 & & 8.21 & Heavily contam. \\
\hline BO045 & Vesime, downstream the urban area & & 1.67 & $\mathrm{Cr}, \mathrm{Ni}$ & 4.03 & Heavily contam. \\
\hline BO047 & Cessole, upstream the urban area & & 1.07 & $\mathrm{Cr}$ & 2.68 & Heavily contam. \\
\hline BO049 & Cessole, downstream the urban area & & 1.76 & $\mathrm{Cr}, \mathrm{Ni}$ & 4.29 & Heavily contam. \\
\hline BO051 & Cessole, downstream the urban area & & 0.92 & $\mathrm{Ni}$ & 2.29 & Mildly contam. \\
\hline BO053 & Bubbio, upstream the urban area & & 2.14 & $\mathrm{Cr}, \mathrm{Ni}$ & 5.16 & Heavily contam. \\
\hline BO055 & Bubbio, downstream the urban area & & 1.70 & $\mathrm{Cr}, \mathrm{Ni}$ & 4.15 & Heavily contam. \\
\hline BO057 & Monastero Bormida, upstream the urban area & $\mathrm{Cr}, \mathrm{Ni}$ & 3.33 & & 7.96 & Heavily contam. \\
\hline BO059 & Monastero Bormida, downstream the urban area & $\mathrm{Cr}, \mathrm{Ni}$ & 4.32 & & 10.18 & Heavily contam. \\
\hline B0061 & Bistagno, confluence with another branch of the Bormida river & $\mathrm{Cr}, \mathrm{Ni}$ & 6.65 & ANPh, ANT, BbF, Chr, FlA, IndPyr, Pyr & 35.32 & Heavily contam. \\
\hline
\end{tabular}

2.2.3.2. Ecotoxicological tests on whole-sediment. Whole-sediment ecotoxicological tests were conducted on undiluted samples with monocotyledonous (Sorghum bicolor) and dicotyledonous plants (Pisum sativum), an ostracod crustacean (Heterocypris incongruens), and a nematode (Caenorhabditis elegans).

Effects of contaminants on germination and root growth rates of seeds were measured following the standard method (UNICHIM, 2003): seeds of $P$. sativum and S. bicolor (25 seeds per replicate, 4 replicates per sample) were exposed to $22.5 \mathrm{~g}$ of sediments for 3 days at $24{ }^{\circ} \mathrm{C}$ in the dark. After exposure, germination and root growth rates were determined.

Survival and growth rates of crustaceans were measured using the Ostracodtoxkit microbiotest (Chial and Persoone, 2002): ostracods (H. incongruens) were exposed to sediment samples in 12-cup polystyrene multiwell plates ( 10 animals per well, 4 replicates per sample) for 6 days at $25{ }^{\circ} \mathrm{C}$ in the dark.

The survival rate of nematodes (C. elegans) after exposure to sediments from a selection of 8 sites was also determined (Peredney, 2004): nematodes (20 synchronized animals at the L3 larval stage per replicate, 4 replicates per sample) were exposed to sediment samples for $24 \mathrm{~h}$ at $20^{\circ} \mathrm{C}$ in the dark.

Table 3

Values of the parameters for the calculation of the ChemRI index in Eq. (3).

\begin{tabular}{|c|c|c|}
\hline Parameter & Symbol & Value \\
\hline First threshold for comparison of $\mathrm{TPC}_{\mathrm{TEC}}$ & $\mathrm{Th}_{1}$ & 1.00 \\
\hline Second threshold for comparison of $\mathrm{TPC}_{\mathrm{TEC}}$ & $\mathrm{Th}_{2}$ & 40.76 \\
\hline Third threshold for comparison of $\mathrm{TPC}_{\mathrm{TEC}}$ & $\mathrm{Th}_{3}$ & 81.52 \\
\hline ChemRI value corresponding to $\mathrm{TPC}_{\mathrm{TEC}}$ levels equal to $\mathrm{Th}_{1}$ & $\alpha_{1}$ & 0.25 \\
\hline ChemRI value corresponding to $\mathrm{TPC}$ TEC levels equal to $\mathrm{Th}_{2}$ & $\alpha_{2}$ & 0.75 \\
\hline
\end{tabular}

2.2.3.3. Ecotoxicological tests on pore-water. Ecotoxicological tests on pore-water were conducted using the bacteria Vibrio fischeri, the protozoa Dictyostelium discoideum, and the nematode C. elegans.

Table 4

Ecotoxicological test realized on the different model organisms: effects due to exposure to sediment samples on high level endpoints were utilized to compute EtoxRI in "heavily contaminated" sites, while sublethal alterations were used to calculate BSI in "mildly contaminated" sediments. All the tests were performed on sediments from the reference sites (BO001 and B0003).

\begin{tabular}{|c|c|c|c|c|}
\hline Organism & Species name & Endpoint & Matrix & $\begin{array}{l}\text { Site } \\
\text { class }\end{array}$ \\
\hline Bacteria & Vibrio fischeri & Bioluminescence & Pore-water & $\mathrm{HC}$ \\
\hline Protozoa & $\begin{array}{l}\text { Dictyostelium } \\
\text { discoideum }\end{array}$ & Survival rate & Pore-water & $\mathrm{HC}$ \\
\hline Protozoa & $\begin{array}{l}\text { Dictyostelium } \\
\text { discoideum }\end{array}$ & $\begin{array}{l}\text { Lysosomal membrane } \\
\text { stability }\end{array}$ & Pore-water & MC \\
\hline Protozoa & $\begin{array}{l}\text { Dictyostelium } \\
\text { discoideum }\end{array}$ & DNA damage & Pore-water & $\mathrm{MC}^{\mathrm{a}}$ \\
\hline Seeds & Pisum sativum & Germination rate & Whole-sediment & $\mathrm{HC}$ \\
\hline Seeds & Pisum sativum & Root growth & Whole-sediment & MC \\
\hline Seeds & Pisum sativum & Mitotic index & Whole-sediment & $\mathrm{MC}^{\mathrm{a}}$ \\
\hline Seeds & Pisum sativum & Mitotic anomalies & Whole-sediment & $\mathrm{MC}^{\mathrm{a}}$ \\
\hline Seeds & Pisum sativum & Micronuclei frequency & Whole-sediment & $\mathrm{MC}^{\mathrm{a}}$ \\
\hline Seeds & Sorghum bicolor & Germination rate & Whole-sediment & $\mathrm{HC}$ \\
\hline Seeds & Sorghum bicolor & Root growth & Whole-sediment & MC \\
\hline Nematods & $\begin{array}{l}\text { Caenorhabditis } \\
\text { elegans }\end{array}$ & Survival rate & Pore-water & $\mathrm{HC}$ \\
\hline Nematods & $\begin{array}{l}\text { Caenorhabditis } \\
\text { elegans }\end{array}$ & Survival rate & Whole-sediment & $\mathrm{HC}^{\mathrm{a}}$ \\
\hline Ostracods & $\begin{array}{l}\text { Heterocypris } \\
\text { incongruens }\end{array}$ & Survival rate & Whole-sediment & $\mathrm{HC}$ \\
\hline Ostracods & $\begin{array}{l}\text { Heterocypris } \\
\text { incongruens }\end{array}$ & Growth rate & Whole-sediment & MC \\
\hline
\end{tabular}

a Tests realized only on a selection of sediment samples. 
In the standard Microtox bacterial luminescence test with $V$. fischeri (ISO, 1998) the reduction in bioluminescence in bacteria is assessed ( $50 \mu \mathrm{L}$ of bacterial culture per replicate, 4 replicates per sample) after $15 \mathrm{~min}$ of exposure to pore-water ( $1 \mathrm{~mL}$ per replicate) at $15^{\circ} \mathrm{C}$.

Protozoa ( $D$. discoideum) were exposed for $3 \mathrm{~h}$ to sediment porewater after which mortality rate as well as lysosomal membrane stability was analyzed as described by Sforzini et al. (2008): cell viability was assessed by observing treated cells after exposure to the DNA-binding dye SYBR Green ${ }^{\mathrm{TM}}$ (Sigma-Aldrich), which allowed discrimination between dead cells (with a fluorescent nucleus) and living cells. The retention time of Neutral Red dye within the lysosomes was used to assess lysosomal membrane stability after exposure to sediment pore-water (Burlando et al., 2002).

The effects of sediment pore-water on the mortality rate of nematodes (C. elegans) were determined following the method described by Ura et al. (2002): nematodes (10 synchronized animals at the L1 larval stage per replicate, 4 replicates per sample) were exposed for $24 \mathrm{~h}$ to sediment pore-water $\left(500 \mu \mathrm{L}\right.$ per replicate) at $20{ }^{\circ} \mathrm{C}$ in the dark.

AIs were calculated setting $\mathrm{Th}_{1}$ and $\mathrm{Th}_{2}$ equal to 0.00 and 0.80 for high level endpoints and to 0.20 and 0.80 for sublethal endpoints (Eq. (4)).

2.2.3.4. Genotoxicity tests. Genotoxicity was determined using protozoa (D. discoideum) and dicotyledonous plants (P. sativum) (Table 4). Protozoa (D. discoideum) were exposed to sediment pore-water as described previously and DNA damage was determined using the comet assay (Siu et al., 2004): cells were fixed with agarose onto a slide, lysed and exposed to an alkaline solution to allow the DNA to denature; electrophoresis was then performed and the slides were fixed in absolute ethanol, dried in air, stained and finally analyzed by microscope; DNA strand breakage was assessed by image analysis.

Genotoxic effects in peas (P. sativum) were assessed on root apices by determining mitotic anomalies, the mitotic index, and micronuclei frequency (Reddy et al., 1995). Mitotic activity was evaluated on stained smears of root apices (Hooker et al., 1998); at least 1000 cells per replicate were scored and the mitotic index as well as the distribution of mitotic phases were calculated. Micronuclei frequency was calculated in root tissues from the number of micronuclei scored divided by the total cells scored (at least 1000 cells per replicate).

As for the other sublethal endpoints, AIs for genotoxic biomarkers were calculated setting $\mathrm{Th}_{1}$ and $\mathrm{Th}_{2}$ equal to 0.20 and 0.80 respectively (Eq. (4)).

\subsubsection{Ecological analysis}

The macroinvertebrate community structure was analyzed by means of determining the IBE index (Ghetti, 1997) at each sampling station: macroinvertebrates were collected with a kick net; the material collected by the net (macroinvertebrates, sediments, inorganic or dead organic material) was subsequently washed and sorted in the field and all macroinvertebrates were fixed in $80 \%$ ethanol; in the laboratory, all organisms were counted and identified to the species or genus level, except for Annelida, early instars of some Trichoptera and Diptera that were identified to the family level (as required by the methodology); in laboratory freshwater invertebrates were analyzed with a Nikon SMZ 1500 light microscope coupled with a videocamera.

AIs of ecological parameters were calculated by comparing IBE index values directly to $\mathrm{Th}_{1}$ and $\mathrm{Th}_{2}$ equal to 10 and 3 respectively (Eq. (4)). In this context IBE values above 10 correspond to high quality environments whereas IBE values below 3 correspond to very low quality environments (Ghetti, 1997).

\section{Results}

Sediments from 31 stations sampled along the Bormida river were classified following comparison of chemical data with TECs and PECs, and calculation of TPCs (Eqs. (1) and (2)). TPC values computed with respect to PECs ranged between 0.00 (BO015, BO021, BO023) and 7.06 (BO029) while those calculated with respect to TEC ranged between 0.13 (BO021) and 35.32 (BO061) (Table 2).

TPC values as well as concentrations of individual contaminants were used to classify sediment samples in terms of contamination levels (Fig. 2). In this regard, sediment samples showing concentrations of at least one contaminant above PEC or having a $\mathrm{TPC}_{\mathrm{PEC}}$ above 1.00 were classified as "heavily contaminated" and selected for high level ecotoxicological bioassays. Sediment samples where the concentrations of all analyzed contaminants were below TEC and the $\mathrm{TPC}_{\mathrm{TEC}}$ was below 1.00 were classified as "uncontaminated" and no further analysis was conducted. The other sediment samples were classified as "mildly contaminated" and selected for sublethal ecotoxicological bioassays. Based on the chemical analysis of sediments sampled from the studied stations, 8 sites were classified as "uncontaminated", 4 as "mildly contaminated" and 19 as "heavily contaminated" (Table 2).

With the aim of verifying the lack of biological effects in organisms exposed to sediments from stations classified as "uncontaminated" on the basis of chemical concentrations, sublethal and high level ecotoxicological tests as well as ecological tests were conducted. No significant alterations were detected in measured biological parameters, thus confirming the absence of false negatives in the processed data set.

A chemical risk index (ChemRI) was calculated for each sampling site (Eq. (3)), where $\mathrm{Th}_{1}$ was set to $1.00, \mathrm{Th}_{2}$ to 40.76 (mean value of the ratios between PECs and TECs) and $\mathrm{Th}_{3}$ to 81.52 (two times $\mathrm{Th}_{2}$ ) (Eq. (6)). The values of ChemRI corresponding to $\mathrm{Th}_{1}$ and $\mathrm{Th}_{2}$ (i.e. $\alpha_{1}$ and $\alpha_{2}$ ) were set to 0.25 and 0.75 , respectively (Table 3 ). ChemRI values ranged from 0.03 (BO015 and BO021) to 0.68 (BO061) (Table 5).

High level endpoints analyzed in model organisms exposed to sediment samples, or to pore-water extracted from sediments classified as "heavily contaminated" indicated a generally low toxicity of the sediments (Table S1; Supporting information), including the two reference sites (BO001 and BO003). No statistically significant

Table 5

Risk indices: ChemRI (all sites), BSI and BVI ("mildly contaminated" sites), EtoxRI, EcoRI, EnvRI, D, and SedRI ("heavily contaminated" sites), GTI (11 sites).

\begin{tabular}{|c|c|c|c|c|c|c|c|c|c|c|}
\hline $\begin{array}{l}\text { Station } \\
\text { code }\end{array}$ & Class & ChemRI & BSI & EtoxRI & EcoRI & GTI & EnvRI & $\mathrm{D}$ & SedRI & BVI \\
\hline BO001 & UC & 0.08 & 0.00 & 0.03 & 0.00 & 0.00 & 0.03 & 0.04 & 0.06 & 0.04 \\
\hline BO003 & UC & 0.07 & 0.00 & 0.03 & 0.29 & NA & 0.15 & 0.14 & 0.05 & 0.04 \\
\hline BO005 & MC & 0.26 & 0.00 & NA & NA & 0.00 & NA & NA & NA & 0.13 \\
\hline BO007 & $\mathrm{HC}$ & 0.41 & NA & 0.12 & 0.38 & 0.29 & 0.30 & 0.16 & 0.27 & NA \\
\hline BO009 & MC & 0.27 & 0.00 & NA & NA & 0.00 & NA & NA & NA & 0.14 \\
\hline BO011 & $\mathrm{HC}$ & 0.36 & NA & 0.06 & 0.29 & NA & 0.23 & 0.15 & 0.21 & NA \\
\hline BO013 & $\mathrm{HC}$ & 0.29 & NA & 0.06 & 0.29 & NA & 0.21 & 0.13 & 0.17 & NA \\
\hline BO015 & UC & 0.03 & NA & NA & NA & NA & NA & NA & NA & NA \\
\hline BO017 & MC & 0.29 & 0.27 & NA & NA & 0.53 & NA & NA & NA & 0.28 \\
\hline BO019 & $\mathrm{HC}$ & 0.38 & NA & 0.10 & 0.29 & 0.44 & 0.25 & 0.14 & 0.24 & NA \\
\hline BO021 & UC & 0.03 & NA & NA & NA & NA & NA & NA & NA & NA \\
\hline BO023 & UC & 0.04 & NA & NA & NA & 0.00 & NA & NA & NA & NA \\
\hline BO025 & UC & 0.14 & NA & NA & NA & NA & NA & NA & NA & NA \\
\hline BO027 & $\mathrm{HC}$ & 0.43 & NA & 0.06 & 0.29 & 0.47 & 0.24 & 0.19 & 0.25 & NA \\
\hline BO029 & $\mathrm{HC}$ & 0.44 & NA & 0.06 & 0.14 & NA & 0.18 & 0.20 & 0.25 & NA \\
\hline BO031 & $\mathrm{HC}$ & 0.39 & NA & 0.06 & 0.38 & 0.33 & 0.28 & 0.19 & 0.22 & NA \\
\hline BO033 & UC & 0.04 & NA & NA & NA & NA & NA & NA & NA & NA \\
\hline BO035 & $\mathrm{HC}$ & 0.33 & NA & 0.24 & 0.29 & 0.49 & 0.28 & 0.05 & 0.28 & NA \\
\hline BO037 & $\mathrm{HC}$ & 0.29 & NA & 0.06 & 0.29 & NA & 0.21 & 0.13 & 0.18 & NA \\
\hline BO039 & UC & 0.24 & NA & NA & NA & NA & NA & NA & NA & NA \\
\hline BO041 & $\mathrm{HC}$ & 0.27 & NA & 0.06 & 0.14 & NA & 0.14 & 0.11 & 0.17 & NA \\
\hline BO043 & $\mathrm{HC}$ & 0.34 & NA & 0.19 & 0.29 & 0.33 & 0.27 & 0.07 & 0.27 & NA \\
\hline BO045 & $\mathrm{HC}$ & 0.29 & NA & 0.09 & 0.33 & NA & 0.24 & 0.13 & 0.19 & NA \\
\hline BO047 & $\mathrm{HC}$ & 0.27 & NA & 0.06 & 0.33 & NA & 0.23 & 0.14 & 0.17 & NA \\
\hline BO049 & $\mathrm{HC}$ & 0.29 & NA & 0.04 & 0.29 & NA & 0.20 & 0.14 & 0.16 & NA \\
\hline BO051 & MC & 0.27 & 0.00 & NA & NA & NA & NA & NA & NA & 0.13 \\
\hline BO053 & $\mathrm{HC}$ & 0.30 & NA & 0.02 & 0.29 & NA & 0.20 & 0.16 & 0.16 & NA \\
\hline BO055 & $\mathrm{HC}$ & 0.29 & NA & 0.07 & 0.29 & NA & 0.21 & 0.13 & 0.18 & NA \\
\hline BO057 & $\mathrm{HC}$ & 0.34 & NA & 0.11 & 0.38 & NA & 0.28 & 0.14 & 0.22 & NA \\
\hline BO059 & $\mathrm{HC}$ & 0.37 & NA & 0.12 & 0.29 & NA & 0.25 & 0.13 & 0.24 & NA \\
\hline BO061 & $\mathrm{HC}$ & 0.68 & NA & 0.04 & 0.33 & NA & 0.31 & 0.32 & 0.36 & NA \\
\hline
\end{tabular}


correlation (Pearson's correlation, $\mathrm{p}>0.05$ ) was evident among the results of the high level ecotoxicological test and granulometry, $\mathrm{pH}$, and organic carbon content in "highly contaminated" sediments, thus confirming that sediment parameters had no relevant influence on toxicological results.

An ecotoxicological risk index (EtoxRI) was calculated on the basis of high level endpoint alterations, showing values ranging from 0.02 (BO053) to 0.24 (BO035), and hence always below the threshold value of 0.25 (Table 5 ).

The benthic macroinvertebrate community structure was analyzed and the IBE index determined at sites classified as "heavily contaminated" (Tables S2 and S3; Supporting information). The results were converted into an ecological risk index (EcoRI) on the basis of IBE values. Calculated EcoRi values ranged from 0.14 (BO029 and BO041) to 0.38 (BO007, BO031, and BO057) (Table 5).

In "heavily contaminated" stations ChemRI, EtoxRI and EcoRI values were also integrated into an environmental risk index (EnvRI) applying different weighting factors (Eq. (5)). EnvRI values ranged from 0.14 (BO041) to 0.31 (BO061) (Table 5).

With the aim verifying the robustness of EnvRI results, a deviation index (D) was calculated as the standard deviation between ChemRI, EtoxRI and EcoRI values. D values for all the sampling sites were always below 0.40 , the threshold value discriminating among reliable and unreliable results (Jensen and Mesman, 2006).

A sediment risk index (SedRI) to assess risks related to sediments from "heavily contaminated" sites was calculated by integrating the ChemRI and the EtoxRI. SedRI values ranged from 0.16 (BO049 and BO053) to 0.36 (BO061) (Table 5).

Sublethal parameters were analyzed from sites classified as "mildly contaminated" as well as from reference samples (BO001, BO003). Only at one sampling station (BO017) the results were significantly different from the reference stations (Table S4; Supporting information). Values of the biological stress index (BSI) were equal to 0.00 for all "mildly contaminated" sites, as well as for the reference sites, with the exception of site BO017 where the BSI index was 0.27 (Table 5).

A biological vulnerability index (BVI) was computed by combining ChemRI and BSI values. BVI values in "mildly contaminated" stations ranged from 0.13 (BO005 and BO051) to 0.28 (BO017) (Table 5).

Finally, genotoxicity tests were performed on a selection of sediment samples, utilizing a social amoeba (D. discoideum) and dicotyledonous plant seeds ( $P$. sativum). The results were integrated into a genotoxic risk index (GTI) to address potential human risks related to environmental carcinogenesis. GTI values ranged from 0.00 (BO001, BO005, B0009, B0023) to 0.53 (BO017) (Table 5).

\section{Discussion}

This study had two major and complementary objectives. The first objective was to develop a suitable data integration system for use in river management. The second objective was to apply the system in a case study in the Bormida river (NW, Italy).

The EDSS is based on an environmental risk assessment tool initially developed for contaminated soils (Dagnino et al., 2008) which has been adapted and modified for application in freshwater ecosystems and, in particular, for the assessment of contaminated sediments.

The EDSS supplies multiple output data: (i) assessment of environmental risk in contaminated areas by integrating chemical, ecotoxicological and ecological data; (ii) assessment of biological vulnerability at sites with low contamination levels by accounting for sublethal biomarker test results; (iii) identification of sites with significant genotoxic contamination levels as evident from model organisms, and indicating a potential hazard to human health; (iv) assessment of sediment quality by integrating chemical and ecotoxicological data.

The different outputs calculated by the EDSS are based on several different indices. ChemRI, EtoxRI (from high level ecotoxicological tests), BSI (from sublethal biomarkers), and EcoRI are all calculated from chemical, ecotoxicological and ecological data and expressed as indices in the range $0-1$. These indices form the scientific basis for the calculation of: (i) the EnvRI index which serves to address the risk of biodiversity reduction in contaminated river basins by integrating triad data (ChemRI, EtoxRI, EcoRI); (ii) the BVI index which is suitable to define the vulnerability level of the moderately contaminated river systems by integrating chemical data (ChemRI) and sublethal biomarker responses (BSI); (iii) the SedRI index which serves to determine sediment quality by means of combining chemical (ChemRI) and ecotoxicological (EtoxRI) results. Finally, an index of genotoxicity (GTI index) can be computed if genotoxic biomarkers are included in the biomarker battery. The GTI index is also suitable to assess chemicals that are potentially harmful to humans.

The proposed integration framework has a similar structure of that proposed by Chapman and Anderson (2005). Both frameworks compare chemical concentrations with threshold levels as a screening step in the risk assessment procedure. However, in our proposed framework, biological tests with endpoints at different levels of biological organization are performed following a chemical site classification based on both the concentrations of single contaminants and the potential additive effects when presented in a mixture. In this regard, high level ecotoxicological tests are only performed on "heavily contaminated" sediments whereas sublethal tests are used to evaluate sediments with intermediate contamination levels. Hence, for each contaminant two different threshold values have been defined, the threshold effect concentration (TEC) and the probable effect concentration (PEC). The TEC represents a threshold concentration of adverse biological effects, and the PEC represents a concentration of toxic effects (MacDonald et al., 2000). Sediments are classified in three different categories by comparing sample concentrations of individual contaminants with their respective TECs and PECs: (i) "uncontaminated"; (ii) "mildly contaminated"; and (iii) "heavily contaminated". Furthermore, at this stage of data analysis potential additive effect is also considered in terms of computing the two different toxic pressure coefficients ( $\mathrm{TPC}_{\mathrm{TEC}}$ and $\mathrm{TPC}_{\mathrm{PEC}}$ ). Samples where $\mathrm{TPC}_{\mathrm{PEC}}$ exceeds 1.00 are classified as "heavily contaminated", even if single contaminant levels are below their respective PECs. Analogously, samples where $\mathrm{TPC}_{\mathrm{TEC}}$ exceeds 1.00 are classified as "mildly contaminated", even if single contaminant levels are below their respective TECs. The use of concentration addition in the calculation of the toxic pressure coefficients represents an established approach, providing a realistic worst case estimation of mixture toxicity (Backhaus and Faust, 2012; Backhaus et al., 2000). Furthermore, the threshold values for $\mathrm{TPC}_{\mathrm{TEC}}$ are deliberately set at conservative levels to ensure a minimum of false-negative samples (i.e. samples falsely classified as "uncontaminated").

The ChemRI index relates to the $\mathrm{TPC}_{\mathrm{TEC}}$ value accordingly: at toxic pressures below the TEC threshold level (i.e. $\mathrm{TPC}_{\mathrm{TEC}}<1$ ), ChemRI is always below the safety threshold level (0.25), whereas at toxic pressure above the PEC threshold level (i.e. $\mathrm{TPC}_{\mathrm{TEC}}>\mathrm{Th}_{2}$ ), ChemRI is always above the high risk threshold level (0.75).

ChemRI values were compared with other indices derived from chemical data and usually applied in ecological risk assessment of sediments: the mean Sediment Quality Guideline Quotient (mSQGQ) proposed by Long et al. (2006), and the Sediment Quality Triad contamination (SQT contamination) proposed by Chapman (1990) and revised by del Valls et al. (1998). Both these methods have similarities with the proposed EDSS: MSQGQ represents the mean value of ratios between sediment concentration and PEC, while SQT contamination represents the mean of ratios between sediment concentrations from the site to be evaluated and those from a reference site. The procedure applied by the EDSS combines these two approaches considering both reference conditions (subtracting background concentration for naturally occurring elements) and the additive toxic pressure of contaminants (comparing concentration to effect-based values, such as TECs and PECs).

Although ChemRI showed statistically significant correlations with these established indices regarding the ranking of sampling sites 
(Spearman's rank correlation, $\mathrm{p}<0.05$, rho: 0.96 and 0.94 , for the comparison between ChemRI and MSQGQ, and SQT contamination, respectively) some innovative features in the proposed framework can be outlined.

ChemRI values derived from $\mathrm{TPC}_{\mathrm{TEC}}$ which accounts for the additive potential toxicity of the analyzed chemicals normalized to TECs: this approach has some similarities with that applied by Long et al. (2006) which compares the level of chemicals to PECs, utilizing the mean value as the final expression of contamination; the main advantage of this latter method is that the result is not dependent on the number of analyzed chemicals but, crucial information about the total additive potential toxicity of sediments is lost. In addition, TPC $\mathrm{TEC}_{\mathrm{TEC}}$ (and consequently ChemRI) is a more conservative expression of sediment contamination than $\mathrm{MSQGQ}$ because it considers TECs instead of PECs as environmental quality standards.

In the computation of ChemRI, also background levels of contamination in the studied area are considered for naturally occurring contaminants, in line with the SQT contamination (Chapman, 1990) and its modifications (del Valls et al., 1998). However, SQT contamination is an index of relative contamination which allows ranking of analyzed sites among each other but does not express any absolute assessment regarding the potential toxicity of sediments.

Finally, ChemRI values range between 0 and 1, allowing for easy interpretation of chemical results in terms of potential risk to the biota.

The results of the high level ecotoxicological tests were used to compute the EtoxRI index in "heavily contaminated" sediments and in the references (BO001 and BO003).

EtoxRI values showed a ranking of the sediments very similar to that obtained applying the most diffuse toxicity indices, such as the SQT toxicity (Chapman, 1990) (Spearman's rank correlation, $\mathrm{p}<0.05$, rho: 0.81) and its modification (del Valls et al., 1998) (Spearman's rank correlation, $\mathrm{p}<0.05$, rho: 0.63 ) thus confirming the reliability of the proposed approach.

Triad data obtained from the Bormida river case study were integrated using the EDSS. At sites classified as "heavily contaminated" based on chemical data (Table 2), the EnvRI showed 8 stations (BO007, BO019, $\mathrm{BO031,} \mathrm{B0035,} \mathrm{BO043,} \mathrm{BO057,} \mathrm{BO059} \mathrm{and} \mathrm{B0061)} \mathrm{to} \mathrm{be} \mathrm{represented}$ by "low risk" (EnvRI in the range $0.25-0.50$ ) whereas the remaining 11 stations as well as the 2 reference sites (BO001, BO003) were represented by "no risk" (EnvRI $<0.25$ ). None of the sites initially classified as "heavily contaminated" were therefore found to represent any significant risk to biota (EnvRI values $>0.50$ ).

The 19 sediment samples classified as "heavily contaminated" on the basis of chemical data were characterized as containing significant levels of pollutants (ChemRI $>0.25$ ) yet with low toxicity on biota as seen from laboratory experiments (EtoxRI $<0.25$ ). This discrepancy can be traced to the results from an ecological survey on the structure of the macroinvertebrate benthic community, results showing only minimal and insignificant disturbance, unlike what was seen at other stations represented by "low risk" to biota (Table 5).

The results further demonstrated that at the time when samples were collected (2006) there was still a certain degree of contamination along the Bormida river, albeit sediments showed low toxicity levels in laboratory tests and the macrobenthic community exhibited results that are comparable to other Italian and European rivers in densely populated areas. In fact, routine monitoring campaigns of the Bormida river have demonstrated that the IBE index has been clearly higher during the last years with respect to what was registered before the closure of the industrial site (Fenoglio, personal communication).

Among sites classified as "heavily contaminated", 13 sites had SedRI values below 0.25 and 6 sites had values in the range 0.25-0.50 (BO007, B0027, B0029, B0035, B0043 and B0061) (Table 5).

Among the 4 sites classified as "mildly contaminated", the BVI index showed low stress levels at all sites (Table 5). Interestingly, the GTI index pointed out one site (BO017) as having a medium risk of genotoxic effects (GTI $\geq 0.50$ ) (Table 5). A chemical analysis showed that sediments sampled from the same site had concentrations below the TECs of all analyzed compounds but the site was nevertheless classified as "mildly contaminated" due to the TPC $\mathrm{TEC}_{\mathrm{TEC}}$ being above the threshold. However, significant alterations in the mitotic activity of $P$. sativum were detected, and also in the root growth tests using both P. sativum and S. bicolor. From the combination of low chemical levels and toxic effects measured in seeds follows the hypothesis that sediments were contaminated by chemicals originating from agricultural activities (e.g. herbicides and pesticides, not analyzed in this study). It is well known that such compounds are rapidly hydrolyzed in the environment (Escher and Fenner, 2011) and that some degradation products may induce genotoxic effects (Bolognesi, 2003; Prado et al., 2009). Furthermore, the GTI index points at the necessity to conduct further studies focusing on possible impact on human health (i.e. environmental carcinogenesis) around sites showing positive responses in genotoxicity tests.

EnvRI values obtained by integrating data from "heavily contaminated" sites and the reference sites (BO001 and BO003) were compared with the indices obtained using the SQT approach (Chapman, 1990; del Valls et al., 1998). The results showed a statistically significant correlation in the ranking of sampling sites (Spearman's rank correlation, rho: $0.86, \mathrm{p}<0.05$ ). However, some differences between the proposed integration framework and the SQT method should be pointed out. The proposed framework clearly separates biological data according to the level of biological organization that they represent: high level ecotoxicological tests are used in sediments from "heavily contaminated" sites to estimate the risk of a biodiversity decline, alongside chemical and ecological data (EnvRI index) and the risk related to sediment exposure (SedRI index). Sublethal biomarkers are measured in sediments from "mildly contaminated" sites to assess the biological vulnerability of impacted organisms (BVI index). BVI allows discriminating sites where although sediments comply with quality standards (i.e. PECs and $\mathrm{TPC}_{\mathrm{PEC}}$ ), they are able to induce a stress syndrome in the organisms, thus potentially reducing their ability to react to additional stressors. This information is crucial in river quality monitoring and risk assessment because it allows environmental managers to identify areas of potential future concern. Moreover, the application of early warning (sublethal) biomarkers in river quality monitoring programs is highly recommended since some of these are also relevant from a human health perspective (biomarkers of endocrine disruption, immunoresponse, and genotoxicity).

In summary, the results obtained from samples taken along the Bormida river have demonstrated downstream areas to be largely recovered seven years after the closure of an upstream industrial plant. However, the integration of biological and chemical analyses allows for classification of sediments not only based on contamination levels but also on bioavailability of contaminants thus improving the reliability of the results and the effectiveness of the eventual remediation interventions. Along the Bormida river, some residual toxicity directly related to the previous industrial activities is still detectable at the innermost sampling site (i.e. BO007). On the other hand, the highest contamination levels were found at a station approximately $60 \mathrm{~km}$ downstream of the industrial site (i.e. B0061). However, this site also receives water from a different branch of the Bormida river bringing waste water from an upstream coke plant, which is likely to increase the level of various PAHs that were found above their TECs in sediments from site B0061.

Triad-based studies usually produce very heterogeneous results that are difficult to interpret objectively and hence provide support to decision-makers and environmental managers. Also, analytical tools able of detecting pollutants at extremely low concentrations have become standard also within environmental monitoring and, consequently, often substantially increase the heterogeneity of the results and hence make it more difficult to attain a correct interpretation.

However, by applying the proposed expert decision support system it is possible to manage a battery of very diverse data from which numerical indices are computed. Such indices are easily interpreted and hence assist in decision-making and environmental management actions, 
e.g. the EnvRI index can assist in identifying sites where remediation actions are necessary or recommended due to an actual decline in biodiversity. Furthermore, sites with little or no effects in high level biological endpoints, but significant effects in sublethal endpoints can be identified from the BVI index. For such sites, the ecosystem can be considered as potentially at risk and monitoring or mitigation actions are recommended. In areas where dredging operations are planned, sediments can be ranked using the SedRI index to determine how dredged materials can be utilized (e.g. re-use of raw material, re-use after treatment, disposal). Finally, risk related to possible human impact can be determined from the GTI index, hence linking environmental and human health risk assessment.

\section{Acknowledgment}

This work was funded by ISPRA (Istituto Superiore per la Protezione e la Ricerca Ambientale) within the frames of the project "Sviluppo di sistemi integrati per la valutazione della qualità dei corpi idrici e la gestione di sedimenti contaminati" and by CeSTA (Centro Sviluppo Tecnologie Ambientali) within the frames of the project "Valutazione del rischio ecologico dei suoli e dei sedimenti fluviali inquinati". Thanks are due to Dr. H. Jonsson for revising the English language.

\section{Appendix A. Supplementary data}

Supplementary data to this article can be found online at http://dx. doi.org/10.1016/j.envint.2013.08.011.

\section{References}

Alvarez-Guerra M, Viguri JR, Voulvoulis N. A multicriteria-based methodology for site prioritisation in sediment management. Environ Int 2009;35(6):920-30.

Apitz SE, Power EA. From risk assessment to sediment management. An international perspective. J Soil Sediment 2002;2(2):61-6.

Backhaus T, Faust M. Predictive environmental risk assessment of chemical mixtures: a conceptual framework. Environ Sci Technol 2012;46(5):2564-73.

Backhaus T, Altenburger R, Boedeker W, Faust M, Scholze M, Grimme LH. Predictability of the toxicity of a multiple mixture of dissimilarly acting chemicals to Vibrio fischeri. Environ Toxicol Chem 2000;19(9):2348-56.

Bay SM, Weisberg SB. Framework for interpreting sediment quality triad data. Integr Environ Assess Manag 2012;8(4):589-96.

Benedetti M, Ciaprini F, Piva F, Onorati F, Fattorini D, Notti A, et al. A multidisciplinary weight of evidence approach for classifying polluted sediments: integrating sediment chemistry, bioavailability, biomarkers responses and bioassays. Environ Int 2012;38(1): 17-28.

Bolognesi C. Genotoxicity of pesticides: a review of human biomonitoring studies. Mutat Res Rev Mutat 2003:543(3):251-72.

Burlando B, Evangelisti V, Dondero F, Pons G, Camakaris J, Viarengo A. Occurrence of Cu-ATPase in Dictyostelium: possible role in resistance to copper. Biochem Biophys Res Commun 2002;291(3):476-83.

Burton GA, Pitt R, Clark S. The role of traditional and novel toxicity test methods in assessing stormwater and sediment contamination. Crit Rev Env Sci Technol 2000;30(4):413-47.

Carr RS, Chapman DC. Comparison of methods for conducting marine and estuarine sediment porewater toxicity tests - extraction, storage and handling techniques. Arch Environ Contam Toxicol 1995;28(1):69-77.

CAS - Chemical Abstracts Service. Specialized substance collections count: CHEMLIST® Chemical Abstracts Service. American Chemical Society; 2013 [Available at: http:/ www.cas.org/content/regulated-chemicals l, accessed 5 August 2013].

Chapman PM. The sediment quality TRIAD approach to determining pollution-induced degradation. Sci Total Environ 1990;97/98:815-25.

Chapman PM. Determining when contamination is pollution - weight of evidence determinations for sediments and effluents. Environ Int 2007;33(4):492-501.

Chapman PM, Anderson J. A decision-making framework for sediment contamination. Integr Environ Assess Manag 2005;1(3):163-73.

Chial B, Persoone G. Cyst-based toxicity tests XIII. Development of a short chronic sediment toxicity test with the ostracod crustacean Heterocypris incongruens: methodology and precision. Environ Toxicol 2002;17(6):528-32.

D'Annibale A, Rosetto F, Leonardi V, Federici F, Petruccioli M. Role of autochthonous filamentous fungi in bioremediation of a soil historically contaminated with aromatic hydrocarbons. Appl Environ Microbiol 2006;72(1):28-36.

Dagnino A, Sforzini S, Dondero F, Fenoglio S, Bona E, Jensen J, et al. A "weight of evidence" approach for the integration of environmental "Triad" data to assess ecological risk and biological vulnerability. Integr Environ Assess Manag 2008;4(3):314-26.

de Deckere E, de Cooman W, Leloup V, Meire P, Schmitt C, von der Ohe PC. Development of sediment quality guidelines for freshwater ecosystems. J Soil Sediment 2011;11(3): 504-17. de Zwart D, Posthuma L. Complex mixture toxicity for single and multiple species: proposed methodologies. Environ Toxicol Chem 2005;24(10):2665-76.

del Valls TA, Forja JM, Gomez-Parra A. Integrative assessment of sediment quality in two littoral ecosystems from the Gulf of Cadiz, Spain. Environ Toxicol Chem 1998;17(6): 1073-84

den Besten PJ, de Deckere E, Babut MP, Power B, del Valls TA, Zago C, et al. Biological effects-based sediment quality in ecological risk assessment for European waters. J Soil Sediment 2003;3(3):144-62.

Escher BI, Fenner K. Recent advances in environmental risk assessment of transformation products. Environ Sci Technol 2011;45(9):3835-47.

European Commission. Directive 2000/60/EC of European Parliament and of the Council of 23rd October 2000 establishing a framework for Community action in the field of water policy. Official Journal of the European CommunitiesBrussels (BE): European Commission; 2000. [L 327/1].

European Union. European Union risk assessment report diantimony trioxide. CAS No: 1309-64-4, Einecs No: 215-175-0. Rapporteur: Sweden: Office for official publications of the European Communities, Luxembourg; 2008.

Fenoglio S, Bo T. Lineamenti di Ecologia Fluviale. Novara: De Agostini Città Studi; 2009 [272 pp.].

Ghetti PF. Manuale di Applicazione: Indice Biotico Esteso - I macroinvertebrati nel controllo della qualità degli ambienti di acque correnti (Application Manual: Extended Biotic Index - Macroinvertebates in Quality Control of Running Water Environments, in Italian); 1997. Provincia Autonoma di Trento, Servizio Protezione Ambiente.

Heise S, Apitz SE, Babut M, Bergmann H, den Besten P, Ellen GJ, et al. Synthesis of the SedNet Work Package 5 Outcomes. J Soil Sediment 2004;4(4):233-5.

Holt MS. Sources of chemical contaminants and routes into the freshwater environment. Food Chem Toxicol 2000;38(S1):S21-7.

Hooker JE, Berta G, Lingua G, Fusconi A, Sgorbati S. Quantification of AM-induced modifications to root system architecture and longevity. In: Varma A, editor. Mycorrhiza manual. Berlin: Springer-Verlag; 1998. p. 515-31.

Horn AL, Rueda FJ, Hormann G, Fohrer N. Implementing river water quality modeling issues in mesoscale watershed models for water policy demands - an overview on current concepts, deficits, and future tasks. Phys Chem Earth 2004;29(11-12):725-37.

Hynes HB. The ecology of flowing waters in relation to management. J Water Pollut Control Fed 1970;42(3):418-24.

ISO (International Standard Organization). Water quality - determination of the inhibitory effect of water samples on the light emission of Vibrio fischeri (luminescent bacteria test). Part 3: method using freeze-dried bacteria. ISO 11348-3. Geneva (CH): International Standard Organization; 1998.

ISPRA (Istituto Superiore per la Protezione e la Ricerca Ambientale). Standard di qualità dei sedimenti fluviali e lacuali. Criteri e Proposta. Rapporti 154/2011, Roma, Italy; 2011 [190 pp.].

Italian Government. Decreto Legislativo 3 aprile 2006, n. 152. Norme in materia ambientaleOfficial Gazette of the Italian Republic, 88; 2006 [14 April].

Jensen J, Mesman M. Ecological risk assessment of contaminated land. Decision support for site specific investigations. Bilthoven, The Netherlands: RIVM; 2006. 136 pp.

Jonker MJ, Svendsen C, Bedaux JJM, Bongers M, Kammenga JE. Significance testing of synergistic/antagonistic, dose level-dependent, or dose ratio-dependent effects in mixture dose-response analysis. Environ Toxicol Chem 2005;24(10):2701-13.

Keddy CJ, Greene JC, Bonnell MA. Review of whole-organism bioassays: soil, freshwater sediment, and freshwater assessment in Canada. Ecotoxicol Environ Saf 1995;30(3): 221-51.

Larsson P. Contaminated sediments of lakes and oceans act as sources of chlorinated hydrocarbons for release to water and atmosphere. Nature 1985;317(6035):347-9.

Long ER, Ingersoll CG, MacDonald DD. Calculation and uses of mean sediment quality guideline quotients: a critical review. Environ Sci Technol 2006;40(6):1726-36.

MacDonald DD, Ingersoll CG, Berger TA. Development and evaluation of consensus-based sediment quality guidelines for freshwater ecosystems. Arch Environ Contam Toxicol 2000;39(1):20-31.

Marengo E, Gennaro MC, Robotti E, Rossanigo P, Rinaudo C, Roz-Gastaldi M. Investigation of anthropic effects connected with metal ions concentration, organic matter and grain size in Bormida river sediments. Anal Chim Acta 2006;560(1-2):172-83.

Massa N, Andreucci F, Poli M, Aceto M, Barbato R, Berta G. Screening for heavy metal accumulators amongst autochthonous plants in a polluted site in Italy. Ecotoxicol Environ Saf 2010;73(8):1988-97.

McDonald BG, De Bruyn AMH, Wernick BG, Patterson L, Pellerin N, Chapman PM. Design and application of a transparent and scalable weight-of-evidence framework: an example from Wabamun lake, Alberta, Canada. Integr Environ Assess Manag 2007;3(4): 476-83.

Newman MC, Ownby DR, Mezin LCA, Powell DC, Christensen TRL, Lerberg SB, et al. Applying species-sensitivity distributions in ecological risk assessment: assumptions of distribution type and sufficient numbers of species. Environ Toxicol Chem 2000;19(2): 508-15.

Norberg-King TJ, Sibley PK, Burton GA, Ingersoll CG, Kemble NE, Ireland S, et al. Interlaboratory evaluation of Hyalella azteca and Chironomus tentans short-term and long-term sediment toxicity tests. Environ Toxicol Chem 2006;25(10):2662-74.

Papa E, Battaini F, Gramatica P. Ranking of aquatic toxicity of esters modelled by QSAR. Chemosphere 2005:58(5):559-70.

Peredney CL. Nematode bioassay protocol for soil toxicity screening. USA: Washington State Department of Ecology; 2004.

Persaud D, Jaagumagi R, Hayton A. Guidelines for the protection and management of aquatic sediment quality in Ontario. Water Resources Branch. Toronto: Ontario Ministry of the Environment; 1993 [32 pp.].

Prado R, Garcia R, Rioboo C, Herrero C, Abalde J, Cid A. Comparison of the sensitivity of different toxicity test endpoints in a microalga exposed to the herbicide paraquat. Environ Int 2009;35(2):240-7. 
Reddy NM, Panda KK, Subhadra AV, Panda BB. The Allium Micronucleus (MNC) Assay may be used to distinguish clastogens from aneugens. Biol Zent Bl 1995;114(4): 358-68.

Salomons W, De Rooij NM, Kerdijk H, Bril J. Sediments as a source for contaminants. Hydrobiologia 1987;149:13-30.

Semenzin E, Critto A, Rutgers M, Marcomini A. Integration of bioavailability, ecology and ecotoxicology by three lines of evidence into ecological risk indexes for contaminated soil assessment. Sci Total Environ 2008;389(1):71-86.

Sforzini S, Dagnino A, Torrielli S, Dondero F, Fenoglio S, Negri A, et al. Use of highly sensitive sublethal stress responses in the social amoeba Dictyostelium discoideum for an assessment of freshwater quality. Sci Total Environ 2008;395(2-3):101-8.

Siu WHL, Cao J, Jack RW, Wu RSS, Richardson BJ, Xu L, et al. Application of the comet and micronucleus assays to the detection of $\mathrm{B}[\mathrm{a}] \mathrm{P}$ genotoxicity in haemocytes of the green-lipped mussel (Perna viridis). Aquat Toxicol 2004;66(4):381-92.

Smutna M, Hilscherova K, Paskova V, Marsalek B. Biochemical parameters in Tubifex tubifex as an integral part of complex sediment toxicity assessment. J Soil Sediment 2008;8(3):154-64.

Struijs J, van de Meent D, Peijnenburg WJGM, van den Hoop MAGT, Crommentuijn T. Added risk approach to derive maximum permissible concentrations for heavy metals: how to take natural background levels into account. Ecotoxicol Environ Saf 1997;37(2):112-8.

UNICHIM (Associazione per l'Unificazione nel settore dell'Industria Chimica). Qualità dell'acqua. Determinazione dell'inibizione della germinazione e allungamento radicale in Cucumis sativum L. (Cetriolo), Lepidium sativum L. (Crescione), Sorghum saccharatum Moench (Sorgo), (saggio di tossicità cronica breve). Milan (IT): UNICHIM; 20031651.

Ura K, Kai T, Sakata S, Iguchi T, Arizono K. Aquatic acute toxicity testing using the nematode Caenorhabditis elegans. J Health Sci 2002;48(6):583-6.

US EPA (United States Environmental Protection Agency). Procedures for the derivation of equilibrium partitioning sediment benchmarks (ESBs) for the protection of benthic organisms: PAH mixtures. EPA-600-R-02-013. Washington, DC: Office of Research and Development; 200320460.

US EPA (United States Environmental Protection Agency). Procedures for the derivation of equilibrium partitioning sediment benchmarks (ESBS) for the protection of benthic organisms: metal mixtures (cadmium, copper, lead, nickel, silver and zinc). EPA-600-R-02-011. Washington, DC: Office of Research and Development; 200520460.

US EPA (United States Environmental Protection Agency). Handbook for developing watershed TMDLs. EPA. Office of Wetlands, Oceans \& Watersheds; 2008 [168 pp.].

van der Hoeven N. Current issues in statistics and models for ecotoxicological risk assessment. Acta Biotheor 2004;52(3):201-17.

van Straalen NM, van Gestel CAM. A stress ecology framework for comprehensive risk assessment of diffuse pollution. Sci Total Environ 2008;406(3):479-83.

van Vlaardingen PLA, Posthumus R, Posthuma-Doodeman JAM. RIVM report 601501029/2005. Environmental Risk Limits for Nine Trace Elements; 2005.

Vink R, Behrendt H, Salomons W. Development of the heavy metal pollution trends in several European rivers: an analysis of point and diffuse sources. Water Sci Technol 1999;39(12):215-23. 